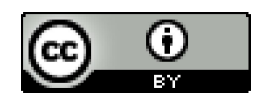

Esta obra está sob o direito de Licença Creative Commons Atribuição 4.0 Internacional.

\title{
PROVIMENTO DO CARGO DE GESTOR ESCOLAR: DA INDICAÇÃO POLÍTICA À ELEIÇÃO DIRETA
}

\author{
Edileuza Gomes dos Santos ${ }^{2}$
}

\section{RESUMO}

Este artigo traz um recorte de uma dissertação de mestrado que analisou as formas do provimento do cargo de gestor e sua influência no modelo de gestão das escolas públicas, tendo como foco o município de Olinda-PE. Para se comprovar essa questão, fez-se necessário investigar especificamente; a indicação política e a eleição, com participação da comunidade escolar; o que se apresenta aqui em forma de artigo. Os resultados obtidos confirmam que a forma do provimento do cargo de gestor não influencia no modelo de gestão da escola a ponto de determiná-lo, visto que outros fatores internos e externos também interferem diretamente nesse contexto. Por fim, recomenda-se que outras formas de provimento do cargo de gestor, com novas estruturas, que respondam melhor aos anseios da contemporaneidade podem e devem ser submetidos à prova, sem que com isso haja retrocesso das questões já reconhecidas, como avançadas.

Palavras-chave: Modelo de gestão. Indicação política. Eleição de gestor.

Submetido em dezembro de 2019 e aceito em janeiro de 2020.

\footnotetext{
2 Possui graduação em Pedagogia pela Faculdade de Ciências Humanas de Olinda (1992), pós graduação em Psicopedagogia pela UPE (2002) e Mestrado em Ciências da Educação, pela Universidade Americana- República del Paraguay (2016).
} 


\section{INTRODUÇÃO}

O desempenho do gestor escolar, frente à instituição que dirige, está condicionado a uma série de elementos e circunstâncias que nem sempre estão atrelados à sua competência técnica $\mathrm{e}$ administrativa. Elementos internos e externos ao contexto escolar tem influência direta em sua forma de gerir a escola. É neste contexto, que o estudo investiga se a forma de provimento do cargo de gestor influencia no modelo de gestão adotado pela escola. Para isso, faz-se necessário também, analisar as duas principais formas de acesso a este cargo: A indicação política e a eleição para gestores.

As teorias aqui apresentadas estão respaldadas à luz dos estudos e pesquisas de autores como: Paro (2000, 2008, 2012, 2015); Dourado (1998); Ferreira (2013); Gadotti (2010); Freire (2005, 2011); Luck (2010, 2011, 2014) e outros. As concepções desses autores serão confrontadas com as informações coletadas em lócus, através de questionários e entrevistas, realizadas com gestores e conselheiros escolares.

A análise dos dados adotará um enfoque misto, também chamado de qualiquanti, pois levará em consideração tanto os aspectos quantitativos, quanto qualitativos, utilizando-se para isso, o método de triangulação concorrente, também chamado por Sampiere (2010, p.570) de "triangulação de dados". Nesse caso, o investigador confirma os resultados e efetua sua validação, cruzando os dados quantitativos e qualitativos.

O marco teórico construído para fundamentar este artigo encontra-se organizado em três seções: Inicialmente são apresentadas as principais formas de provimento do cargo de gestor escolar adotadas no Brasil, com ênfase à indicação política e a eleição; em seguida se apresentam pesquisas que tratam de avanços, entraves e expectativas em relação à eleição; por fim, uma análise crítica da postura do gestor eleito, no exercício de sua função.

O estudo partiu da premissa de que a forma de provimento ao cargo de gestor, influencia no modelo de gestão adotado na escola. No entanto, os teóricos pesquisados, assim como os dados coletados durante a pesquisa, comprovam que o modelo de gestão da escola é resultante de uma série de fatores, onde a forma de acesso ao cargo de gestor não é um fator determinante.

Preliminarmente ao discorrimento sobre essas duas formas de acesso ao cargo de gestor, faz-se necessário compreender outras formas de provimento a este cargo, ainda existentes no Brasil, mesmo não sendo objeto desse estudo, torna-se necessário conhecê-las.

Dentro do contexto educacional brasileiro, ainda é possivel encontrar 
diversos mecanismos de provimento do cargo de gestor escolar - seja para gerir as escolas públicas municipais ou estaduais. Entre as formas comumente utilizadas, destacam- se: 1) diretor livremente indicado pelos poderes públicos (estados e municípios); 2) diretor de carreira; 3) diretor aprovado em concurso público; 4) diretor indicado por listas tríplices ou sêxtuplas, os também chamados processos mistos; e 5) eleição direta para diretor. (Caderno 5/ Programa de Fortalecimento dos Conselhos Escolares/MEC 2004).

Estes mesmos mecanismos ou modalidades são apresentados por Dourado (2013), com a seguinte nomenclatura e definição: a) Indicativa, forma de acesso na qual os representantes políticos indicam os gestores; b) Direta, onde a comunidade escolar pode votar no gestor mais qualificado para o cargo; c) Seletiva, por meio de uma prova específica em que se verifica se o candidato a gestor está munido dos conhecimentos necessários para exercer a função; d) Seletiva e Direta, neste caso, dá-se por meio de concurso, ou outra forma de seleção e, após classificados, os candidatos são submetidos à aceitação da comunidade, através do voto ou da aprovação de suas propostas de gestão.

Algumas dessas modalidades passaram a ser menos utilizadas com o decorrer dos anos e outras foram surgindo mediante às novas concepções de educação e de gestão, levanto-se em consideração, também, posições políticas e ideológicas dos dirigentes locais durante os seus respectivos mandatos.

Apesar dessas constatações, as duas formas de acesso ao cargo de gestor escolar em maior incidência no Brasil, atualmente, são a eleição direta e a indicação política, portanto, são a essas duas formas a que se detém esse estudo.

Historicamente justificada, a escolha de Diretor e Vice-Diretor de Escolas públicas vinham sendo de competência exclusiva do chefe do Poder Executivo, nas três esferas de Governo, servindo, muitas vezes, de instrumento de acomodações políticas. Todavia, as práticas administrativas ou os modelos de gestão dessas escolas dirigidas por pessoas indicadas por força de injunções políticas acabavam sendo associadas a gestões ineficientes, além de refratárias às práticas modernas ditadas pela pedagogia, ou pelo modelo de administração gerencial que tem sido adotado mundo afora.

Em suma, a indicação política ou livre indicação é aquela em que o gestor escolar é conduzido a este cargo de confiança, por indicação de um gestor público. Na maioria dos casos, pautado na troca de favores, nos interesses pessoais e eleitoreiros ou ainda por pressão partidária.

Nesse caso, as autoridades do executivo faziam - e ainda fazem - as suas 
indicações sem o respaldo da comunidade escolar. Conforme excerto extraído do caderno 5, fornecido pelo MEC, que trata sobre o Fortalecimento dos Conselhos Escolares:

Essa modalidade articulada ao conservadorismo político permitia, portanto, a transformação da escola em um espaço instrumentalizador de práticas autoritárias e mecanismo de barganhas políticas as mais diversas, evidenciando forte ingerência na gestão escola.

Esse espaço de barganha política em que a escola se transformou também é criticado por Dourado (2013), quando ele o chama de "curral” eleitoral. Tal expressão é usada no meio político para indicar o poder de opressão dos dominantes; no caso em questão, essa opressão se materializa pela imposição do nome do gestor, sem que a comunidade escolar possa opinar ou questionar essa decisão.

\section{METODOLOGIA}

Foi desenvolvida uma revisão de literatura, não sistemática, de natureza qualitativa descritiva. Utilizou-se como fonte de pesquisa livros e documentos

\section{RESULTADOS E DISCUSSÕES}

Ao analisar as formas de provimento do cargo de gestor escolar, em maior incidência no Brasil, percebe-se que a
Já o processo de eleição para gestores, pode apresentar-se de diversas formas, dependendo do modelo traçado, das condições operacionais ou das limitações encontradas pelos órgãos executores. Ele pode sofrer alterações desde o colégio eleitoral - que pode se restringir a uma parte da comunidade escolar ou a sua totalidade até o estabelecimento de certos mecanismos de avaliação, como: provas específicas, apresentação de planos de trabalho, participação em cursos de formação etc.

Não por acaso, essa modalidade de acesso ao cargo de gestor é a mais polêmica. É defendida por todos que acreditam que esse é um mecanismo legítimo para a redemocratização da escola e das relações sociais mais amplas. Mas é criticada por outros, que não acreditam ou que deixaram de acreditar por terem suas expectativas frustradas em relação a tal processo.

obtidos de bibliotecas físicas e virtuais. As categorias temáticas desenvolvidas após análise das fontes foram: eleição ou indicação: O que dizem as pesquisas? e uma análise crítica da postura do gestor eleito.

eleição é a forma mais utilizada pelos Estados e Municípios, que veem neste mecanismo um passo significativo no sentido de garantir a democratização da gestão; já à indicação política - segunda 
forma de provimento ao cargo de gestor ainda utilizada -, esta é vista como um retrocesso, diante das atuais discussões sobre gestão democrática e participativa.

É consenso também entre os teóricos que a eleição por si só não garante a efetivação da gestão democrática, contudo é um caminho que leva a outros princípios defendidos por este modelo de gestão, como: a crescente autonomia da escola, a descentralização da gestão, uma maior participação da comunidade escolar, criação ou fortalecimento, - onde já se têm, de fóruns de discussão, conselhos de gestores, conselhos escolares, grêmios estudantis, dentre outros mecanismos de participação. Sabe-se, porém, que a democratização da escola está atrelada à democratização da própria sociedade, o que implica uma luta que ultrapassa os muros das escolas.

Em consonância com esses teóricos, os sujeitos participantes da pesquisa, apontam como sendo esses os principais responsáveis pelo modelo de gestão implantado pela escola: A forma como o gestor atua em sua administração; o grau de autonomia em que o Conselho Escolar e a própria escola se encontram; o nível de integração e participação da comunidade escolar; as orientações emanadas de Secretaria de Educação e o nível de maturidade política da comunidade onde a escola se insere.
Em suas falas, observa-se que a presença da comunidade na escola e o reconhecimento da importância do Conselho Escolar nos momentos decisórios da escola, precisa se dar de forma mais permanente e não apenas em momentos pontuais, como é o caso da eleição para gestores. Para os participantes da pesquisa esse é um movimento legítimo e natural, independente da escola ser gerida por um gestor eleito ou indicado.

Percebe-se consenso também, entre os gestores entrevistados, ao afirmar que não existe nenhum impedimento por parte deles ou da Secretaria de Educação para que práticas democráticas sejam implantadas na escola, independente da forma de ascensão ao cargo, ao contrário, essas práticas são estimuladas e garantidas; possibilitando assim, um progressivo grau de autonomia à escola e, consequentemente, ao gestor escolar, na condução da sua gestão.

Quanto às dificuldades apontadas pelos gestores no desempenho de suas funções, não foi feita nenhuma relação com a forma de provimento do cargo e sim com as especificidades de cada espaço educacional, o contexto social em que ele se insere e empecilhos inerentes ao próprio funcionamento da escola.

Com base nessas evidências, confirma-se que a forma de provimento do cargo de gestor; seja por indicação, seja por eleição, não influencia no modelo de gestão 
implantado na escola a ponto de defini-lo, e que esta definição se dá a partir da junção de muitos outros fatores, aqui apresentados.

\section{Eleição ou indicação: o que dizem as pesquisas?}

Fatores como competência, excelência, produtividade nem sempre estão associados à forma de provimento do cargo de gestor, valendo-se a mesma observação quando este não atende às exigências da função. Em se tratando dessas questões, seguem resultados de duas pesquisas realizadas no Brasil e que em muito podem contribuir para essa discussão.

Entre 1991 e 1993, Vitor Henrique Paro realizou uma pesquisa pela Universidade de São Paulo intitulada Eleição de diretores de escolas públicas: Avanços e limites da prática. O objetivo do autor era analisar comparativamente experiências de eleição de diretores de escolas de $1^{\circ}$ e $2^{\circ}$ graus no país, visando a estudar características e problemas de sua institucionalização e implementação, bem como captar seus efeitos sobre a democratização da gestão escolar e sobre a qualidade/quantidade na oferta de ensino. (PARO, 2001).

Ao analisar o estudo do autor, verificam-se algumas limitações enfrentadas no processo de eleição para gestores, tanto em relação à sua implementação, quanto em relação às expectativas que se tinha a esse respeito. A principal crença que existia em torno das eleições de diretores, segundo Paro, era de que a eleição neutralizaria as práticas tradicionalistas calcadas no clientelismo e no favorecimento pessoal - o que não foi garantido com o pleito.

Apesar de a pesquisa apontar, em alguns Estados, para uma diminuição ou eliminação da influência dos agentes políticos, as práticas clientelistas continuaram fazendo parte do interior de algumas escolas, quer no processo de eleição do diretor, quer durante o exercício do mandato.

Paro (2001) relata que a conservação da influência políticopartidária também foi constatada em alguns locais onde a eleição se deu por lista tríplice, uma vez que a escolha definitiva de um dos três nomes fica por conta do Poder Executivo. E mais, nos locais em que não havia essa forma de acesso ao cargo, alguns oportunistas, valendo-se de sua influência e experiência política, utilizaram-se de outros artifícios, com a intenção de influenciar no resultado do pleito.

O autor explica que tais acontecimentos justificam-se pela incipiente prática política, que ainda não é capaz de eliminar por completo essas expectativas e comportamentos clientelistas - que nada mais são do que remanescentes de uma cultura tradicionalista -, e que só a 
prática da democracia e o exercício autônomo da cidadania poderão superar.

Outra expectativa frustrada, segundo o pesquisador, é que muitas pessoas acreditavam que a eleição conseguiria eliminar o autoritarismo existente na escola, e a falta de participação da comunidade escolar também seria outro aspecto superado. No entanto, a eleição direta para gestor também não foi capaz de atender a essas expectativas.

Paro (2001) esclarece que muito das características do chefe monocrático, que detém a autoridade máxima na escola, persistiu mesmo com a eleição. E a participação tão esperada não aconteceu a contento. E mais uma vez, o pesquisador chama a atenção para o fato de que é preciso considerar que não se trata de culpar a eleição por tais fatos, mas de reconhecer que o autoritarismo ainda presente nas escolas é resultado da conjunção de uma série de determinantes internos e externos à unidade escolar e que, sem uma cultura desenvolvida de participação social, é muito difícil conseguir que os indivíduos não deleguem a outros aquilo que faz parte de sua obrigação enquanto sujeito partícipe da ação coletiva.

Outra circunstância, presente na pesquisa é que a eleição não está imune ao corporativismo por parte dos grupos que interagem na escola, a exemplo dos docentes. A esse respeito, o autor menciona relatos de autoridades das secretarias de educação que alegam a existência de acordos internos, favorecimento a grupos que se propõem a oferecer apoio a um determinado candidato ao cargo de gestor seja antes, durante ou após o processo eleitoral.

Ao analisar essas questões, Paro diz que uma importante característica da eleição é que, especificamente em sociedade com fortes marcas tradicionalistas, sem uma cultura de participação social, a escolha democrática de um líder - como é o caso do gestor de escola - pode significar a oportunidade de jogar sobre os ombros do outro toda a responsabilidade que envolve a prática escolar.

E para respaldar sua afirmativa, Paro se vale de Dourado (1990, p. 139) que se refere a esse tipo de situação como a uma "redução do processo democrático", ou seja, "mera delegação de poderes". Já Holmesland et al. (1989, p. 138) considera que "o diretor de escola pública, mesmo eleito, é um indivíduo que tende a sentir-se desacompanhado, desprotegido, solitário."

Além de apresentar esses impasses e limitações em relação à eleição para dirigentes escolares, o autor deixa claro que esse processo de escolha do gestor é apenas um dos múltiplos determinantes que influencia na maneira de gerir a escola, e que essa não é a única forma de acesso ao 
cargo. E sendo a falta de tradição democrática um dos grandes entraves, será apenas com a insistência em mecanismos de participação e de exercício da democracia que se conseguirá maior envolvimento de todos em suas responsabilidades.

Por fim, Paro (2001) afirma que passar de uma situação clientelista - onde o que vale é o critério político-partidário para uma situação de escolha democrática legitimada pela vontade dos sujeitos envolvidos na situação escolar -, implica em muitas mudanças. Mudanças essas que nem sempre a comunidade escolar está preparada para fazer.

Outra pesquisa, aqui destacada, foi realizada pela Revista Nova Escola, intitulada "Práticas de Seleção e Capacitação de Diretores Escolares". Promovida pela Área de Estudos e Pesquisas Educacionais da FVC (Fundação Victor Civita) e coordenada por Heloísa Lück, diretora educacional do Centro de Desenvolvimento Humano Aplicado (Cedhap), em Curitiba. Tal pesquisa revela que a eleição é a forma mais utilizada para selecionar gestores nos estados brasileiros.

Segundo a Revista, participaram do estudo - realizado entre maio e novembro de 2010, e divulgado em março de 2011 Secretarias de Educação de 24 unidades federativas e de 11 capitais. E envolveu 107 gestores, organizados em 14 grupos de discussão.
O referido estudo aponta que o meio de acesso predominante à função de gestor escolar é a eleição direta, realizada pela comunidade escolar, e utilizada por $67 \%$ das secretarias estaduais e $82 \%$ das municipais.

A pesquisa ressalta que é comum que exista mais de uma modalidade de seleção em um mesmo lugar. Em algumas localidades onde acontece a eleição, essa pode ser precedida de uma prova ou uma certificação, que serviriam para diminuir o número de aspirantes à vaga; podendo conviver com a indicação de prefeitos, governadores e secretários - artifício utilizado quando a escola não apresenta condições objetivas para a realização do pleito ou não se apresentaram candidatos aptos ao exercício da função.

Além desses dados, a pesquisa também traz algumas queixas dos diretores ouvidos nos grupos de discussão, no que tange ao processo de eleição. Como exemplo disso, pode haver o "clima pesado" existente durante a época de campanha. $\mathrm{O}$ motivo pode ser o fato de que nem sempre o candidato mais preparado é o eleito, já que muitas vezes quem vence é o mais carismático ou o que promove alianças com o corpo docente ou outro segmento do eleitorado.

Outra dificuldade apontada é o tempo de permanência no cargo: ao ser eleita, a maior parte dos diretores cumpre 
um mandato de dois ou três anos -período que os especialistas consideram curto para empreender grandes transformações. "Além disso, como vão ficar pouco tempo na função, os gestores não buscam maior profissionalização", explica Marta Luz Sisson de Castro, professora da Pontifícia Universidade Católica do Rio Grande do Sul (PUC-RS).

\section{Uma análise crítica da postura do gestor eleito}

É fato que esse modelo de escolha representativa trouxe consigo ganhos efetivos ao processo de gestão democrática. Todavia, passados quase 20 anos dessa vivência, faz-se necessário reavaliar as implicações advindas dessa prática e quais os resultados obtidos especialmente no campo dos avanços das políticas de ensino.

Para tanto, é válido refletir e analisar como vem sendo desenvolvidas as principais dimensões da gestão escolar, em particular: o político, o pedagógico e o administrativo-financeiro. Tendo como parâmetro o que se espera desse gestor, eleito democraticamente, no pleno exercício de sua função.

No que tange ao primeiro deles, o político, em uma determinada época, acreditava-se que a eleição direta para diretor escolar constituía-se num espaço de maior participação e interferência da comunidade escolar e local - o que significava também, contribuir e interferir nas políticas educacionais do país, no entanto, em âmbito geral, não se tem comprovação de que isso aconteceu.

A relação da Escola com a comunidade local (família e lideranças comunitárias) pouco ou nada se fortaleceu. Mesmo tendo acento no Conselho Escolar, é pouco visível a participação dos pais, alunos e funcionários no que diz respeito à construção, execução e avaliação do Projeto Político-Pedagógico vivenciado pela escola.

Em relação à postura de alguns gestores, antes, visto como articulador político, defensor dos interesses coletivos e das causas trabalhistas, dentre outras competências, pós eleição, agora como representante de um órgão estatal, passa a defender outros interesses, inclusive, evitando que os interesses dos primeiros se sobreponham aos interesses do segundo.

Paro (2008, p.133) explica como se dá essa situação de dualidade em que o gestor se encontra, ora tendo que atender às pressões e reivindicações dos professores e demais integrantes da escola, ora tendo que defender os interesses do Poder Público.

Assim, como educador que é, e identificado com os objetivos legítimos da instituição que dirige, ele se sente compelido a atender às justas reivindicações da escola e da comunidade ou pelo menos - no caso de ser impotente 
para atendê-las - engajar-se como uma voz a mais a exigir soluções dos órgãos superiores. Entretanto em seu papel de gerente (é assim que ele é colocado diante do Estado), ele sente sobre si todo o peso de constituir-se no responsável último pelo cumprimento da Lei e da Ordem na escola e tem consciência de que poderá ser punido por qualquer irregularidade que aí se verifique. (PARO, 2008, p. 133-134).

Outra postura contraditória dos gestores eleitos é quanto à definição de sua posição política. Enquanto alguns, fazendo uso do prestígio adquirido com a nova função, detêm-se às barganhas e conchavos político-partidários, cujo principal objetivo é o de se manter no cargo e de auferir os benefícios dele decorrente; outros, entretanto, apoiam-se no discurso apolítico, como se educação e política fossem algo incompatível entre si.

Essa postura extremista também não é salutar, haja vista que mesmo não estando sob o "apadrinhamento" político, mas ocupando uma função legitimada pelo voto, não há por que $\mathrm{o}$ gestor ignorar $\mathrm{o}$ pensamento político governante. Até porque a perda de apoio político poderia comprometer sua atuação enquanto gestor, tornando-o uma liderança frágil e isolada. E o projeto político-pedagógico da escola poderia se desarticular da política educacional da rede - não esquecendo que a educação também é uma ação política.
Reforçando esse entendimento, cabe aqui o pensamento de Paulo Freire (2011, p.109) quando diz que "para que a educação não fosse uma forma política de intervenção no mundo, era indispensável que o mundo em que ela se desse não fosse humano". Nessa mesma linha de pensamento, Freire, já disse: "os principais problemas da educação não são as questões pedagógicas, e $\operatorname{sim}$ as questões políticas". Disso se depreende que não é possível fazer educação sem visualizar a dimensão política desse ato.

Sabendo-se que o processo eleitoral efetivou-se contando com a participação de todos os atores envolvidos no ambiente escolar (pais, alunos, professores e funcionários), esperava-se, ainda, que o sentimento/ comportamento "opressoroprimido" não mais aparecesse nas relações de trabalho estabelecidas dentro desses espaços. Não obstante, alguns gestores eleitos permanecem com as mesmas posturas autoritárias de outrora, ou seja, permanecem com a mesma ideologia de quem detém o poder, detém o comando; portanto, todos devem subordinar-se a ele.

Não considerando tal postura como correta, ainda cabe aqui uma reflexão sobre como é difícil para o ser humano abster-se de determinadas posturas que são inerentes à sua formação, enquanto sujeito de uma sociedade essencialmente opressora. 
O grande problema está em como poderão os oprimidos que "hospedam" o opressor em si, participar de elaboração, como seres duplos, inautênticos, da pedagogia de sua libertação. Somente na medida em que se descubram "hospedeiros" do opressor poderão contribuir para o partejamento de sua pedagogia libertadora. (FREIRE, 2011, p.34).

Com isso, Freire esclarece que mudar da posição de oprimido para a de opressor é apenas uma questão de oportunidade, e que para sair dessa condição que a nova função lhe conferiu, o gestor precisa se reconhecer como o oprimido que é e o opressor que se tornou.

Não obstante, é possível comprovar que, decorrente das várias atribuições que assume, esse gestor tem se revestido mais dos aspectos burocráticos, técnicos e financeiros; em detrimento do pedagógico o que deveria ser sua missão primeira, já que esta dimensão da gestão, justifica todas as outras.

Com isso, "o diretor se vê gradativamente tolhido em sua função de educador, já que pouco tempo lhe resta para dedicar-se às atividades mais diretamente

\section{CONCLUSÃO}

Ainda que a pesquisa comprove que a forma de provimento ao cargo de gestor, isoladamente, não influencia no modelo de ligadas aos problemas pedagógicos no interior da escola". (PARO, 2008, p.133).

Mais uma vez recorrendo a Paro (2001), Freire (2011) e Luck (2000), embora se tratando de obras distintas, confirma-se que as dimensões da gestão aqui destacadas não acontecem de forma estanque, nem dissociadas uma das outras.

As questões pedagógicas, administrativas, políticas e financeiras fazem parte de um todo que se materializa na prática do gestor. Prática essa que dificilmente ele dará conta sem dividir tal responsabilidade com os demais integrantes da escola, exigindo, assim, uma gestão participativa e democrática.

Apesar das considerações aqui apresentadas, reconhece-se que o modelo de eleição direta para gestor escolar vem cumprido o seu papel, seja na perspectiva de buscar novos caminhos quanto à alternância de poder; na transparência das ações desenvolvidas na escola, em uma maior participação da comunidade escolar e, por fim, com vistas a atender seu objetivo macro: o de ofertar uma educação com qualidade social para todo.

gestão da escola, confirma-se que a eleição tem sido a forma mais discutida $\mathrm{e}$ defendida, enquanto canal legítimo de luta pela democratização da escola e como forma de efetivar essa gestão democrática e 
participativa tão discutida. Enquanto a indicação política, como único critério para ascensão a este cargo, não cabe mais, dentro do modelo educacional vigente. No entanto, é ingênuo acreditar que a eleição sozinha irá democratizar a gestão das escolas, ou erradicar a influência políticopartidária, com suas (in)conveniências e interesses, seja por parte do poder público,

\section{REFERÊNCIAS}

DOURADO, L. F. A escolha de dirigentes escolares: Políticas e gestão da educação no Brasil. In: FERREIRA, N. S. C (Org.) Gestão Democrática da Educação: atuais tendências, novos desafios. 6.ed., São Paulo: Cortez, 2008.

FERREIRA, N.S. C. Gestão democrática da educação: atuais tendências, novos desafios. 8. ed. São Paulo: Cortez, 2013.

FREIRE, P. Pedagogia da autonomia: saberes necessários à prática educativa. São Paulo: Paz e Terra, 2011.

FREIRE, P. Pedagogia do oprimido. Rio de Janeiro: Paz e Terra, 2005.

GADOTTI, M. Escola cidadã. 13. ed. São Paulo: Cortez, 2010.

LEAL, V. N. Coronelismo, enxada e voto. 4. ed. São Paulo: Companhia das Letras, 2012.

LIBÂNEO, J. C. Organização e Gestão da escola: teoria e prática. Goiânia: Alternativa, 2001.

LÜCK, H. Perspectivas da Gestão Escolar e Implicações quanto à Formação de seus Gestores. Em Aberto, Brasília, v. 17, n. 72, p.11-33, 2000. Semestral. dos ocupantes do cargo de gestor ou de outros integrantes da escola. Com isso, o estudo aqui apresentado traz grande contribuição para o meio acadêmico, que pesquisa e debate sobre o as formas de provimento ao cargo de gestor escolar, além de servir de parâmetro para outros Estados e Municípios que adotam ou pretendem adotar algum dos modelos aqui analisados.

PARO, V H. Administração Escolar: Introdução crítica. 17. ed. São Paulo: Cortez, 2012.

PARO, V H. Formação de gestores escolares: a atualidade, 2008.

SAMPIERE, R.H et al. Metodología de la investigación. 5. Ed. editora Mcgraw Hill, 2010.

SANTOS, J. E. dos. A Eleição de Gestores Escolares em Pernambuco: continuidades e rupturas na política de democratização da Escola Pública. UFPE. Recife, 2009.

VIEIRA, S. L.; MEDEIROS, Isabel Letícia Pedroso de. Gestão escolar democrática: concepções e vivências. Porto Alegre: Editora da UFRGS, 2006. 